\title{
RO Resection for Locally Advanced Pancreatic Cancer with Low-dose Gemcitabine with Wide Irradiation Area as Neoadjuvant Chemoradiotherapy
}

\author{
HIROFUMI KAMACHI ${ }^{1}$, YOUSUKE TSURUGA ${ }^{1}$, TATSUYA ORIMO ${ }^{1}$, KENJI WAKAYAMA $^{1}$, SHINGO SHIMADA $^{1}$, \\ AKIHISA NAGATSU ${ }^{1}$, HIDEKI YOKOO ${ }^{1}$, TOSHIYA KAMIYAMA ${ }^{1}$, NORIO KATOH $^{2}$ and AKINOBU TAKETOMI ${ }^{1}$ \\ Department of ${ }^{1}$ Gastroenterological Surgery I, and ${ }^{2}$ Radiation Medicine, \\ Graduate School of Medicine, Hokkaido University, Sapporo, Japan
}

\begin{abstract}
Background: Local antitumor efficacy and the outcome of neoadjuvant chemoradiotherapy (NACRT) with low-dose gemcitabine and wide irradiation area for borderline resectable and unresectable pancreatic cancer were evaluated. Patients and Methods: Thirty-four cases of borderline resectable and unresectable pancreatic cancer were recruited. Three-dimensional conformal radiotherapy to the pancreatic bed and the region scheduled for lymph node dissection was performed to a total dose of 50.4 Gy 28 fractions with gemcitabine at a dose of $150 \mathrm{mg} / \mathrm{m}^{2}$ weekly. Clinical and pathological results were examined. Results: Twenty-seven patients $(79.4 \%)$ completed the protocol. Grade 3/4 leucopenia $(n=10)$, and grade 3 anorexia $(n=1)$ occurred. Seven cases were excluded (two refused treatment; five had progressive disease), 20 underwent laparotomy, and 16 resected $(47.1 \%)$ cases achieved $R 0$ resection. Median survival time, and 3-year and 5-year survival rates were 39.0 months, and $56.3 \%$ and $28.1 \%$ in resected cases, respectively. Conclusion: NACRT with low-dose gemcitabine and wide irradiation area achieved $100 \%$ RO resection and acceptable prognosis.
\end{abstract}

Pancreatic ductal adenocarcinoma (PDAC) has recently increased in incidence and is the fourth to sixth leading cause of cancer-related death in Western countries and Japan (1). This disease has a poor prognosis, with a 5-year survival rate

This article is freely accessible online.

Correspondence to: Hirofumi Kamachi, MD, Ph.D., Department of Gastroenterological Surgery I, Graduate School of Medicine, Hokkaido University. N-15, W-7, Kita-ku, Sapporo, Hokkaido, 0600838, Japan. Tel: +81 117065927, Fax: +81 117177515, e-mail: hkamachi@db3.so-net.ne.jp

Key Words: Neoadjuvant, chemoradiotherapy, pancreatic cancer, gemcitabine, $\mathrm{R} 0$ resection. of around 5\% for patients overall (2, 3). Adjuvant chemotherapy with gemcitabine or S-1 after $81-88 \%$ of R0 surgical resections improved patient outcome, resulting in a 5-year survival rate of 20-24\% with gemcitabine (4-6) and $44 \%$ with S-1 (7). Although R0 surgical resection is a prognosis factor for long-term survival, 15-85\% of surgical resections were margin-positive, which are associated with worse overall survival (8-10).

A standard therapeutic strategy for PDAC was proposed by the National Comprehensive Cancer Network (NCCN) guideline according to disease progression (11). Regarding the local progression of tumors, several criteria define resectability into three categories: potentially resectable, borderline resectable (BR), and unresectable (UR) (12-14). These categories are defined by the degree of tumor invasion in the vascular structure such as superior mesenteric vein (SMV) and portal vein (PV), and in arteries such as superior mesenteric artery (SMA), common hepatic artery (CHA) and celiac artery (CA). For BR PDAC, neoadjuvant therapy prior to surgery is recommended by the NCCN guideline (11).

As neoadjuvant therapy for BR to UR PDAC, we introduced gemcitabine-based neoadjuvant chemoradiotherapy (NACRT) which is intended to achieve R0 resection. Our focus is on controlling micrometastasis to surrounding tissues, thus our regimen has the characteristic feature of being applied to a wide irradiation area, which includes not only the tumor and surrounding area, but also the area of lymph node dissection, CA-CHA, and SMA nerve plexus. Here, we report the results of our gemcitabine-based neoadjuvant chemoradiotherapy based on this concept.

\section{Patients and Methods}

Patient examination and definition of $B R$ and UR PDAC. Between January 2006 and 2013, 34 patients with histologically proven BR and UR PDAC were enrolled for our gemcitabine-based NACRT protocol. Multidetector computed tomography (MDCT), contrastenhanced ultrasonography (CEUS), gadoxetic acid-enhanced 
magnetic resonance imaging, and ${ }^{18} \mathrm{~F}$-fluorodeoxyglucose (FDG) positron-emission tomography (PET) were performed to examine local progression and distant metastasis. The definition of BR and UR PDAC followed the guidelines of a National Cancer Institutedesignated National Comprehensive Cancer Network (NCCN) (14).

Neoadjuvant treatment plan and assessment. This study was performed with the approval of the Internal Review Board on ethical issues at Hokkaido University Hospital, Sapporo, Japan (approval number 008-0040). All procedures performed in studies involving human participants were in accordance with the ethical standards of the institutional and/or national research committee and with the 1964 Helsinki declaration and its later amendments or comparable ethical standards. Informed consent was obtained from all individual participants included in the study

All patients were treated with three-dimensional conformal radiotherapy using the 3 -or 4-field technique from directions that avoided exposure of the kidney, an organ at risk. Based on the CT images, the gross tumor volume (GTV), which included the main tumor and lymph nodes of more than $1 \mathrm{~cm}$ in diameter, was defined. Clinical target volume 1 (CVT1) was defined as the GTV plus a 5$\mathrm{mm}$ margin in all directions, and CVT2 was defined as the field that contained the regional lymph nodes prescribed by sixth edition of the Union for International Cancer Control TNM classification (15) and extrapancreatic nerve plexus along with SMA and CA-CHA The planning target volume (PTV) was basically defined as CTV1 and CTV2 plus a uniform 15-mm margin, which comprised the internal and the set-up margins (Figure 1). The total radiation dose delivered was 50.4 Gy in 28 fractions (five fractions/week). The dose was prescribed at the center of the PTV. The dose constraints for organs at risk were as follows: spinal cord: maximum dose $<45 \mathrm{~Gy}$; liver: volume of the liver receiving a dose of at least 35 Gy (V35)<33\%; kidney: V20 of both kidneys $<50 \%$ and V20 of each individual kidney $<67 \%$.

Patients were administered an infusion of gemcitabine at a dosage of $150 \mathrm{mg} / \mathrm{m}^{2}$ weekly. Within 4-6 weeks after the completion of NACRT, the patients were reassessed by CT, MRI and FDG-PET. If we determined that resection with curative-intent was possible, surgery was performed.

Safety assessment was performed before each cycle with the use of the National Cancer Institute Common Terminology Criteria for Adverse Events (CTCAE v4.0) (16). Tumor response was determined according to the Response Evaluation Criteria in Solid Tumors (RECIST) (17)

Surgical procedure and postoperative complications. Pancreaticoduodenectomy and distal pancreatectomy were performed according to conventional methods $(18,19)$. Requirement of resection and reconstruction of PV and SMV were judged when it was not possible to detached the vessels from the tumor and were performed at an arbitrary time. Dissection of the pancreatic nerve plexus was basically performed as follows: dissection of the nerve plexus of hepatoduodenum ligament, $\mathrm{CHA}$, right side of $\mathrm{CA}$, and right side of SMA was undertaken for pancreaticoduodenectomy, and dissection of nerve plexus of CHA, left side of CA, and left side of SMA was performed for distal pancreatectomy. Additional nerve plexus dissection was performed according to the tumor extension to nerve plexus evaluated by MDCT before NACRT.

Postoperative complications were graded according to the Clavien-Dindo classification (20). Postoperative pancreatic fistula was graded according to the International Study Group on Pancreatic Fistula classification (21).

Postoperative follow-up. After discharge, administration of gemcitabine or S-1 for at least 6 months was planned. All patients were evaluated every 3 months by physical examination and laboratory tests including serum levels of carcinoembryonic antigen (CEA) and cancer antigen (CA)19-9, plus MDCT.

Evaluation of histological response. Formalin-fixed and paraffinembedded specimens were retrieved from the surgical pathology files of the Pathology Department of Hokkaido University Hospital. Sections were cut and stained with hematoxylin-eosin (H\&E) for routine histopathological examination. Histological response to neoadjuvant chemoradiotherapy was evaluated according to Evans et al.'s histological criteria (22).

Statistical analysis. Comparison of categorical variables was performed using Fisher's exact test, and continuous variables were analyzed by Mann-Whitney rank-sum test. Statistical significance was defined as a $p$-value of less than 0.05 . Kaplan-Meier curves were used to determine survival, with the date of neoadjuvant initiation as time 0 . All statistical analyses were performed using statistical analysis software (JMP Pro 13.1.0 for Windows; SAS Institute Inc. Cary, NC, USA).

\section{Results}

Preoperative characteristics of enrolled patients. According to the definitions of BR and UR PDAC described above, of the 34 enrolled patients, disease in 28 was classified as BR and in six as UR. PV-SMV involvement was confirmed in $18(52.9 \%)$ patients, and arterial involvement was confirmed in $26(76.5 \%)$ patients (Table I). Reasons for disease being defined as UR was the finding of tumor abutment of the SMA exceeding greater than 180 degrees of the circumference in five patients, and PV-SMV occlusion in one patient. Twenty-seven patients $(79.4 \%)$ completed NACRT, and 16 patients $(47.1 \%)$ underwent resection with curative intent. Grade 3 or higher adverse effects in white blood cell/neutrophil counts defined by CTCAE ver 4.0 occurred in 10 patients (37\%) and the relative dose intensity of gemcitabine was $85.2 \%$. During the study, nine patients $(26.3 \%)$ were excluded from resection criteria because of distant metastasis, and two patients (5.9\%) with local progression were excluded. The flow of all 34 patients through the treatment schema is depicted in Figure 2.

Tumor response to NACRT and surgical results. The tumor responses of the 27 patients who completed the NACRT protocol were analyzed (Table II). Local tumor response assessed by RECIST criteria were as follows: partial response was observed in eight $(29.6 \%)$ patients, stable disease in $14(51.9 \%)$ patients, and progression disease in four $(14.8 \%)$ patients. Median reduction ratio of the value of CA19-9 before and after NACRT was $54.6 \%$ and that of 

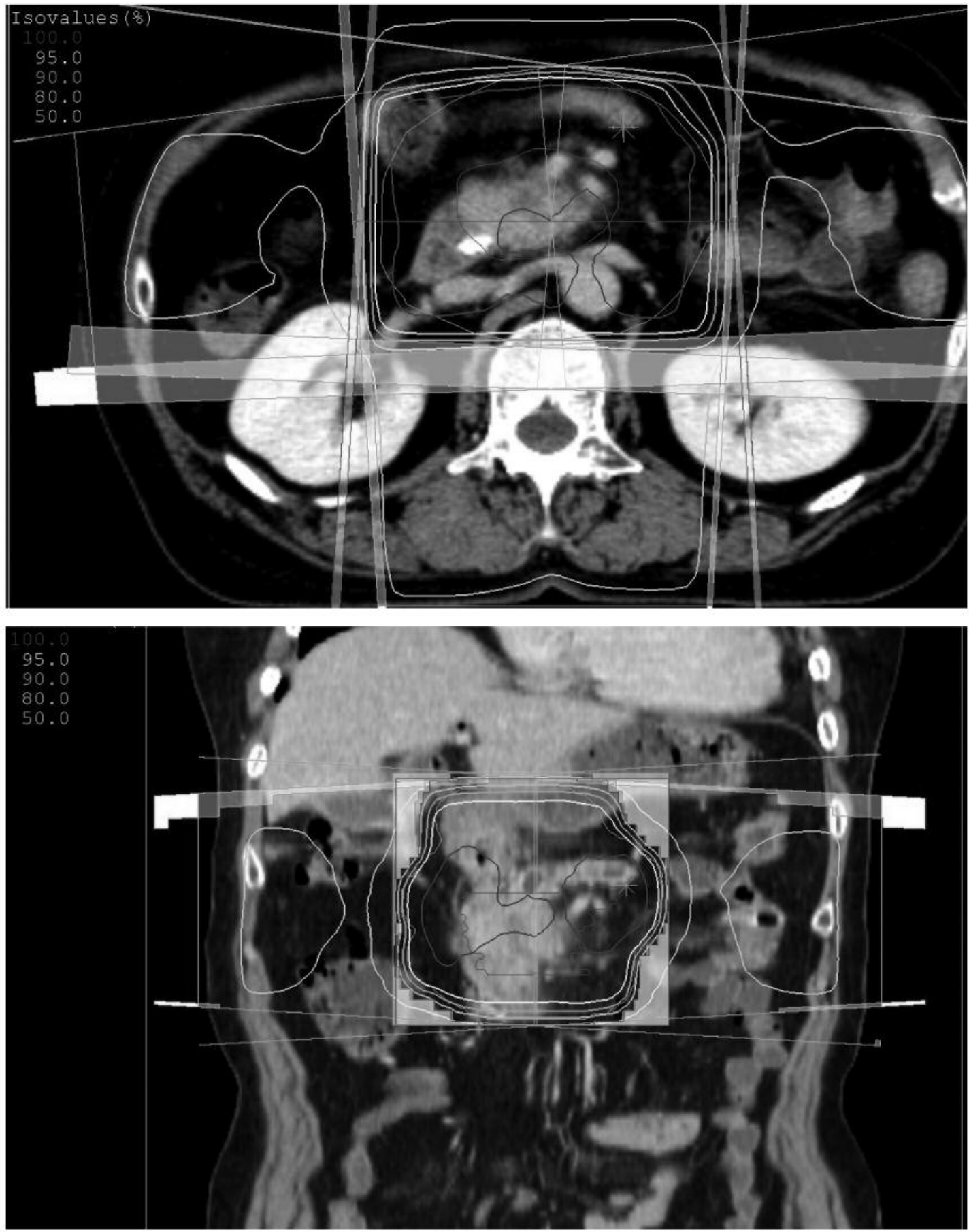

Figure 1. Irradiation area of three-dimensional conformal radiotherapy using the 4-field technique. Images indicate typical isodose lines encompassing a region including not only the tumor but also a lymph node dissection area.

FDG-PET SUV value was $53.7 \%$. These parameters did not statistically significantly differ between the resected and unresected groups. Finally, 16 out of 34 patients underwent surgical resection with curative intent. Total pancreatectomy was performed in one case. PV/SMV resection was performed in $12(75.0 \%)$ patients and hepatic arterial resection was performed in one $(6.25 \%)$ patient. ClavianDindo classification IIIa was observed in four (25.0\%) and 


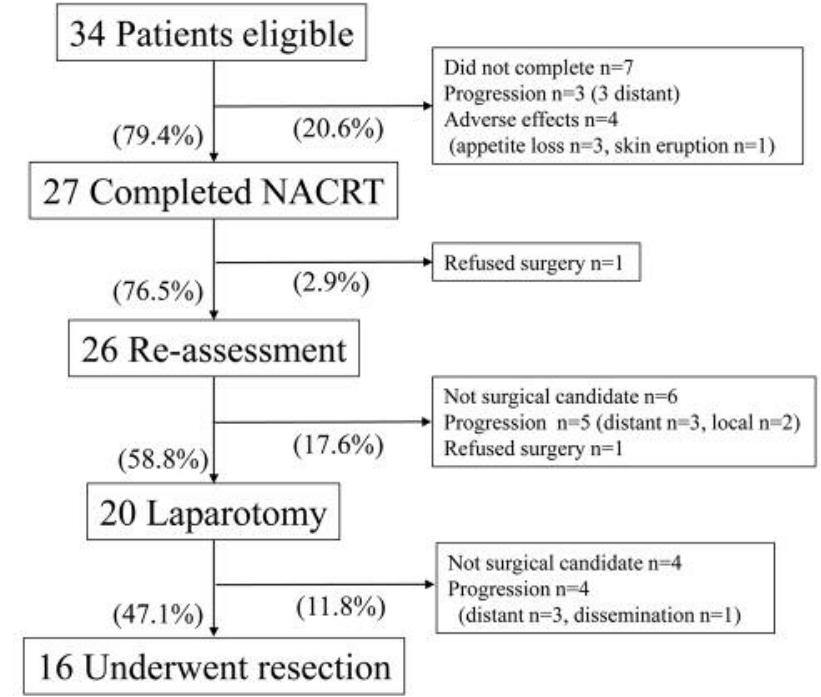

Figure 2. Treatment schema. Thirty-four patients with borderline resectable (BR) and unresectable (UR) pancreatic adenocarcinoma met the study inclusion criteria. Twenty-seven patients (79.4\%) completed neoadjuvant chemoradiotherapy (NACRT), and $16(47.1 \%)$ underwent resection with curative intent.

there were no patients over Clavian-Dindo IIIb. According to an international study group of postoperative pancreas fistula definition (21), pancreatic fistula grade B occurred in three patients $(18.8 \%)$, including both cases treated by distal pancreatectomy.

Pathological results. Pathological stage T3 was observed in 15 patients $(93.7 \%)$ and only one patient achieved downstaging to T2 (Table II). Four patients (25\%) had lymph node metastasis, but only five (1.0\%) lymph nodes were metastatic amongst 495 dissected lymph nodes from 16 patients who underwent resection.

According to Evans et al.'s histological criteria, nine out of 16 patients (56.3\%) were classified over grade IIb, which meant more than $50 \%$ tumor cells were destroyed by NACRT. As a result, $100 \%$ R0 resection was achieved in these 16 patients.

Patient outcome. The survival period was calculated based on the time from when NACRT was started. Intention-to-treat analysis of all 34 patients showed that the median overall survival time (MST) was 19.9 months (Figure 3A). The MST, and 3-and 5-year overall survival rates of resected patients (with 39.0 months of median follow-up duration) were 39.0 months, and $56.2 \%$ and $28.1 \%$, respectively, and those of unresected patients were 14.9 months, and $0.0 \%$ and $0.0 \%$, respectively $(p<0.001)$ (Figure 3B). MST of unresected patients with
Table I. Preoperative characteristics of enrolled patients $(n=34)$.

\begin{tabular}{|c|c|}
\hline Variable & All $(n=34)$ \\
\hline \multicolumn{2}{|l|}{ Age, years } \\
\hline Median (range) & $62.5(44-78)$ \\
\hline \multicolumn{2}{|l|}{ Gender, $\mathrm{n}$} \\
\hline Male/female & $20 / 14$ \\
\hline \multicolumn{2}{|l|}{ Tumor location, $\mathrm{n}$} \\
\hline Head-uncinate/body-tail & $26 / 8$ \\
\hline \multicolumn{2}{|l|}{ Tumor size before NACRT, mm } \\
\hline Median (range) & $30(15-54)$ \\
\hline \multicolumn{2}{|l|}{ Vessel involvement: $\mathrm{n}(\%)$} \\
\hline SMV/PV involvement & $18(52.9)$ \\
\hline CHA abutment and encasement to HA & $5(14.7)$ \\
\hline SMA abutment not $>180^{\circ}$ & $16(47.1)$ \\
\hline SMA abutment $\geq 180^{\circ}$ & $5(14.7)$ \\
\hline \multicolumn{2}{|l|}{ Resectability status n $(\%)^{\#}$} \\
\hline Borderline & $28(82.4)$ \\
\hline Unresectable & $6(17.6)$ \\
\hline \multicolumn{2}{|l|}{ NACRT, n (\%) } \\
\hline Completion rate & $27(79.4)$ \\
\hline \multicolumn{2}{|l|}{ Reason for discontinuation } \\
\hline Distant metastases & $3(8.8)$ \\
\hline Adverse effect & $4(11.8)$ \\
\hline \multicolumn{2}{|l|}{ RDI of gemcitabine, $\%$} \\
\hline Median (range)* & $85.2 \%(50-100)$ \\
\hline \multicolumn{2}{|l|}{ Adverse effect n (\%) } \\
\hline White blood cell/neutrophil decrease & $10(37)$ \\
\hline Anorexia & $1(3.7)$ \\
\hline Pneumonitis & $1(3.7)$ \\
\hline \multicolumn{2}{|l|}{ Laparotomy rate $\mathrm{n}(\%)$} \\
\hline Overall & $20(58.8)$ \\
\hline \multicolumn{2}{|l|}{ Reason for abandoning laparotomy } \\
\hline Distant metastases & $3(8.8)$ \\
\hline Local progression & $2(5.9)$ \\
\hline Patient request & $2(5.9)$ \\
\hline \multicolumn{2}{|l|}{ Resection rate $\mathrm{n}(\%)$} \\
\hline Overall & $16(47.1)$ \\
\hline \multicolumn{2}{|l|}{ Reason for abandoning resection } \\
\hline Distant metastases & $4(11.8)$ \\
\hline Local progression & $0(0.0)$ \\
\hline
\end{tabular}

NACRT: Neoadjuvant chemoradiotherapy; RDI: relative dose intensity; SMV: superior mesenteric vein; PV: portal vein; SMA: superior mesenteric artery; CHA: common hepatic artery; HA: hepatic artery; CA: celiac artery. "By NCCN definition. *For patients who completed NACRT. $* *$ Grade 3 or higher of CTCAE ver. 4.0.

completion of NACRT and without completion of NACRT were 14.9 months, and 8.3 months, respectively $(p=0.0326)$. Among the 16 patients who completed NACRT and underwent surgical resection, 13 (81.3\%) developed recurrence; the median time to recurrence was 14.9 months (range=1.3-33.5 months) (Figure 3C). The first sites of recurrence were as follows: 10 patients $(62.5 \%)$ had distant organ metastasis (five liver, five lung), one patient (6.25\%) had peritoneal dissemination, and two patients $(12.5 \%)$ had local recurrence. 
Table II. Outcome of patients who completed neoadjuvant chemoradiotherapy (NACRT) ( $n=26 *)$.

\begin{tabular}{|c|c|c|c|}
\hline Variable & $\begin{array}{c}\text { Resected } \\
(\mathrm{n}=16)\end{array}$ & $\begin{array}{l}\text { Not resected } \\
\quad(\mathrm{n}=10)\end{array}$ & $p$-Value \\
\hline \multicolumn{4}{|l|}{ Local response } \\
\hline CR & 0 & 0 & 0.612 \\
\hline PR & 6 & 2 & \\
\hline SD & 0 & 6 & \\
\hline $\mathrm{PD}$ & 2 & 2 & \\
\hline \multicolumn{4}{|l|}{ Median CA19-9 (range), U/ml } \\
\hline Before NACRT & $47.45(11.4-605.9)$ & $124.35(24.1-3122.8)$ & 0.1354 \\
\hline Perioperative & $24.1(5.1-210.5)$ & $4.7(7.5-202.93)$ & 0.2439 \\
\hline Reduction rate $(\%)$ & 53.3 & 64.8 & 0.5923 \\
\hline \multicolumn{4}{|l|}{ Median FDG-PET SUV (range) } \\
\hline Before NACRT & $6.0(3.09-13.964)$ & $8.461(2.7-13.1)$ & 0.6977 \\
\hline Perioperative & $3.3(0-6.551)$ & $3.68(1.73-6.6)$ & 0.4598 \\
\hline Reduction rate $(\%)$ & 53.7 & 54.5 & 0.8577 \\
\hline \multicolumn{4}{|l|}{ Operative procedure n (\%) } \\
\hline Pancreaticoduodenectomy & $13(81.3)$ & & \\
\hline Distal pancreatectomy & $2(12.5)$ & & \\
\hline Total pancreatectomy & $1(6.25)$ & & \\
\hline $\mathrm{PV} / \mathrm{SMV}$ resection/reconstruction & $12(75.0)$ & & \\
\hline Arterial resection/reconstruction & $1(6.25)$ & & \\
\hline \multicolumn{4}{|l|}{ Blood loss, $\mathrm{ml}$} \\
\hline Median (range) & $642(180-2620)$ & & \\
\hline \multicolumn{4}{|l|}{ Operative time, $\min$} \\
\hline Median (range) & $600(458-834)$ & & \\
\hline \multicolumn{4}{|l|}{ Clavien-Dindo classification n (\%) } \\
\hline I & $8(50.0)$ & & \\
\hline II & $4(25.0)$ & & \\
\hline IIIa & $4(25.0)$ & & \\
\hline \multicolumn{4}{|l|}{ ISGPF classification, $\mathrm{n}(\%)$} \\
\hline A & $0(0.0)$ & & \\
\hline $\mathrm{B}$ & $3(18.8)$ & & \\
\hline $\mathrm{C}$ & $0(0.0)$ & & \\
\hline \multicolumn{4}{|l|}{ Evans grade, $\mathrm{n}$} \\
\hline I & 1 & & \\
\hline $\mathrm{IIa} / \mathrm{IIb}$ & $6 / 7$ & & \\
\hline III/IIIM & $1 / 1$ & & \\
\hline IV & 0 & & \\
\hline$\geq \mathrm{IIb}, \mathrm{n}(\%)$ & $9(56.3)$ & & \\
\hline \multicolumn{4}{|l|}{ Pathological stage, n (\%) } \\
\hline $\mathrm{T} 1$ & $0(0.0)$ & & \\
\hline $\mathrm{T} 2$ & $1(6.3)$ & & \\
\hline $\mathrm{T} 3$ & $15(93.7)$ & & \\
\hline No & $12(75.0)$ & & \\
\hline $\mathrm{N} 1$ & $4(25.0)$ & & \\
\hline \multicolumn{4}{|l|}{$\mathrm{LN}, \mathrm{n}(\%)$} \\
\hline Metastatic/total & $5 / 498(1.0)$ & & \\
\hline R0 operation, n (\%) & $16(100)$ & & \\
\hline
\end{tabular}

NACRT: Neoadjuvant chemoradiotherapy; SMV: superior mesenteric vein; PV: portal vein; SMA: superior mesenteric artery; CR: complete response; PR: partial response; SD: stable disease; PD: progressive disease; FDG-PET: 18F-fluorodeoxyglucose positron-emission tomography; SUV: standardized uptake value; LN: lymph node. *One patient was excluded due to refusal of reassessment and surgery.

\section{Discussion}

R0 surgical resection is considered to be one of the essential prognostic factors for predicting long-term survival of patients with PDAC (8-10). For locally advanced PDAC, neoadjuvant therapies are recommended in the NCCN guidelines. There are many points to consider when selecting neoadjuvant therapy, such as chemotherapy or 

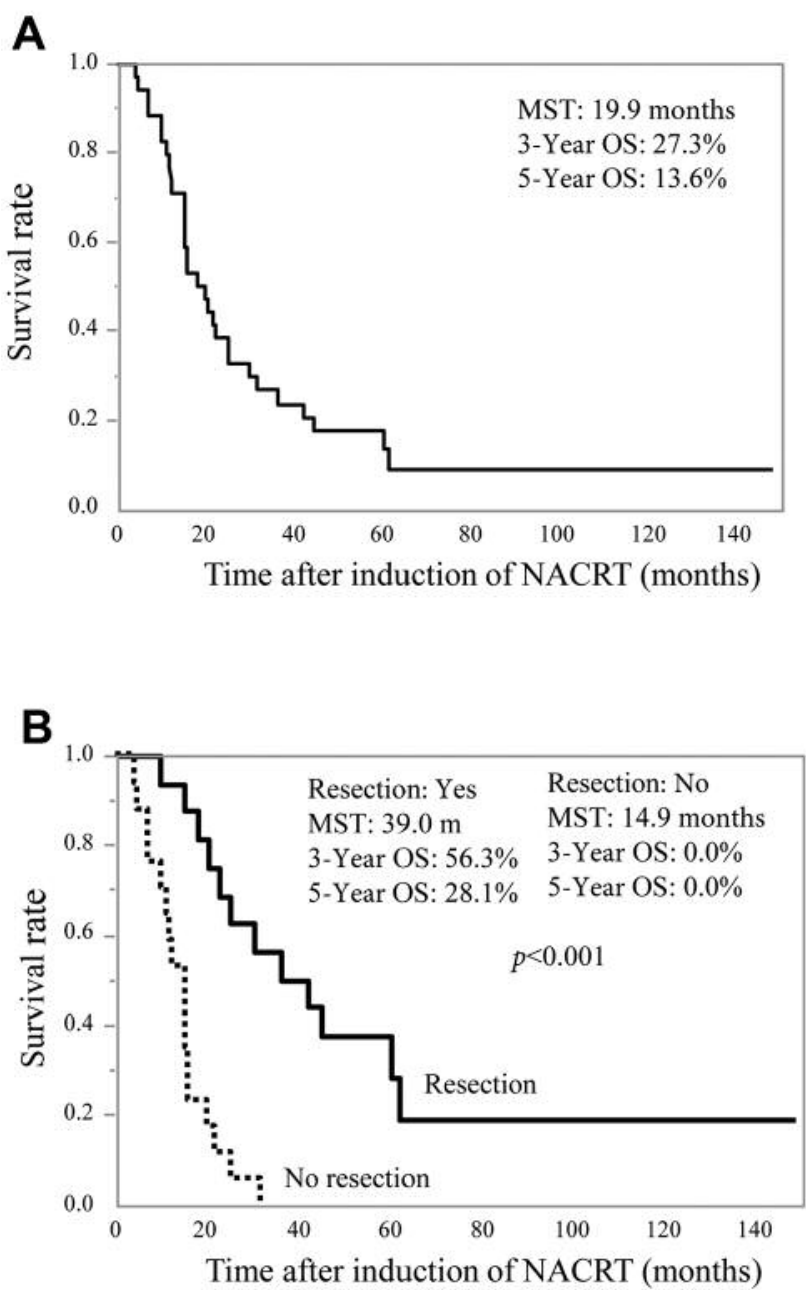

C Recurrence-free survival of resected cases.

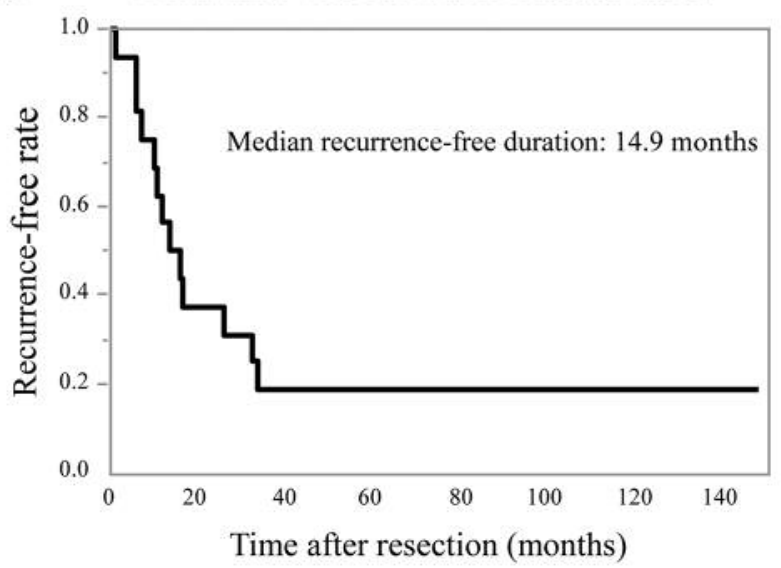

Figure 3. Patient outcome. A: Intention-to-treat analysis of all 34 patients showed that median overall survival time (MST) was 19.9 months. B: MST, 3-year and 5-year overall survival rates of the patients who underwent resection and those who did not. C: Median recurrencefree time of patients who underwent resection was 14.9 months. chemoradiotherapy, antitumor agent, and method of radiation. NACRT is considered to achieve a high R0 surgical resection rate, with rates of $94 \%$ (23) and 98\% (24) previously reported. To achieve $\mathrm{R} 0$ resection, we intended to control micrometastases that had spread to surrounding tissue, lymph nodes, and nerve plexus by applying a wide irradiation area. Of the various antitumor agents tested for NACRT $(23,25-$ 28), we selected gemcitabine as a radiosensitive agent (29). Various doses of gemcitabine, from full dose at $1,000 \mathrm{mg} / \mathrm{m}^{2}$ (24) to $50 \mathrm{mg} / \mathrm{m}^{2}$ (30) were administered for gemcitabinebased NACRT $(31,32)$; we administered low-dose gemcitabine in our protocol, according to past experience of chemoradiotherapy against recurrent lesions. However, despite this low-dose, R0 resection was achieved in all 16 patients treated using our protocol.

We then examined the acceptable locoregional effects of our NACRT protocol on tumor. The histological criteria of Evans et al. showed that more than half of the resected cases $(56.3 \%)$ were judged to be over grade IIb. This result was similar to past reports $(23,26,28)$, but Takahashi et al. reported that NACRT with full-dose gemcitabine resulted in Evans histological criteria over grade III (more than $90 \%$ tumor cells injured) in $16 \%$ of resected cases (24). This suggests the possibility of enhancing the local antitumor effect by using more potent anticancer drugs. The grade of pathological response after NACRT influenced patient prognosis in rectal cancer $(33,34)$ and gastro-esophageal cancer (35). The relationship between anticancer drug, pathological response, and prognosis in neoadjuvant therapy for PDAC should be considered in the future.

NACRT for PDAC is thought to reduce local recurrence and lymphatic nodal metastasis. Groot et al. reported that the local recurrence rate in 1103 patients with PDAC was at least $43 \%$ (36). However, the local recurrence rate after NACRT was reported as $9-14 \%(23,24)$, and our data showed a local recurrence rate of $12.5 \%$. Regarding lymph node metastasis, 12 out of 16 patients $(75 \%)$ were negative for lymph node metastasis, and the proportion of positive lymph node metastasis was only $1.0 \%$ in all dissected lymph nodes. These results were comparable to other reports demonstrating negative lymph node metastasis rates of 61$81 \%(23,24,26)$. Regarding the local effect, NACRT with low-dose gemcitabine was also effective. We speculate that irradiation would be more important for the locoregional effects on the tumor than the selection of antitumor agents.

It is necessary to discuss the systemic effects resulting from the use of low-dose gemcitabine in NACRT. The resection rate after NACRT for BR PDAC differs in literature, ranging from $40-88.8 \%(23,24,26,28,30,32,37)$. The resection rate in our protocol was $47.1 \%$, and nine patients $(26.3 \%)$ were excluded from the resection criteria after exhibiting distant metastasis during the neoadjuvant therapy. Takahashi et al. (24) reported the results of NACRT with full-dose gemcitabine 
for 80 BR PDAC patients; the resection rate was $47.1 \%$, and 11 patients $(13.8 \%)$ were excluded because of distant metastasis (28). Kobayashi et al. reported the results of NACRT with gemcitabine administered at $800 \mathrm{mg} / \mathrm{m}^{2}$ weekly for 44 patients with BR PDAC; the resection rate was $81.8 \%$, and six patients $(13.6 \%)$ were excluded because of distant metastasis (32). This suggests that the dose of gemcitabine during NACRT would influence the occurrence of distant metastasis.

However, high resection rates are not necessarily related to patient prognosis. Kim et al. reported a resection rate of $61.5 \%$ and MST of 25.4 months for patients treated with NACRT with full-dose gemcitabine and oxaliplatin (28). As previously mentioned, Kobayashi et al reported an $81.8 \%$ resection rate and MST of 24.3 months (32). The MST of our protocol was 39.0 months, while Katz et al. reported MST of 40 months, with a $41.3 \%$ resection rate and $20.6 \%$ distant metastasis (23). If there is a role of 'patient selection' in NACRT, in that patients that potentially have distant metastasis are excluded, our NACRT protocol with low-dose gemcitabine might select for patients more strictly as good prognosis was obtained in resected cases.

\section{Conclusion}

In conclusion, NACRT with low-dose gemcitabine and wide irradiation area for locally advanced PDAC provided acceptable locoregional effects and resulted in a high rate of $\mathrm{R} 0$ resection. In addition, a good prognosis was obtained in resected cases. To increase the resection rate and achieve better prognosis, there is a need to enhance systemic effects using other more effective antitumor drugs.

\section{Conflicts of Internet}

The Authors have no financial relationships to disclose.

\section{Acknowledgements}

The Authors thank H. Nikki March, Ph.D., from Edanz Group (www.edanzediting.com/ac) for editing a draft of this article.

\section{References}

1 Fitzmaurice C, Dicker D, Pain A, Hamavid H, Moradi-Lakeh M, MacIntyre MF, Allen C, Hansen G, Woodbrook R, Wolfe C, Hamadeh RR, Moore A, Werdecker A, Gessner BD, Te Ao B, McMahon B, Karimkhani C, Yu C, Cooke GS, Schwebel DC, Carpenter DO, Pereira DM, Nash D, Kazi DS, De Leo D, Plass D, Ukwaja KN, Thurston GD, Yun Jin K, Simard EP, Mills E, Park EK, Catala-Lopez F, deVeber G, Gotay C, Khan G, Hosgood HD, 3rd, Santos IS, Leasher JL, Singh J, Leigh J, Jonas JB, Sanabria J, Beardsley J, Jacobsen KH, Takahashi K, Franklin RC, Ronfani L, Montico M, Naldi L, Tonelli M, Geleijnse J, Petzold M, Shrime MG, Younis M, Yonemoto N, Breitborde N,
Yip P, Pourmalek F, Lotufo PA, Esteghamati A, Hankey GJ, Ali R, Lunevicius R, Malekzadeh R, Dellavalle R, Weintraub R, Lucas R, Hay R, Rojas-Rueda D, Westerman R, Sepanlou SG, Nolte S, Patten S, Weichenthal S, Abera SF, Fereshtehnejad SM, Shiue I, Driscoll T, Vasankari T, Alsharif U, Rahimi-Movaghar V, Vlassov VV, Marcenes WS, Mekonnen W, Melaku YA, Yano Y, Artaman A, Campos I, MacLachlan J, Mueller U, Kim D, Trillini M, Eshrati B, Williams HC, Shibuya K, Dandona R, Murthy K, Cowie B, Amare AT, Antonio CA, Castaneda-Orjuela C, van Gool CH, Violante F, Oh IH, Deribe K, Soreide K, Knibbs L, Kereselidze M, Green M, Cardenas R, Roy N, Tillmann T, Li Y, Krueger H, Monasta L, Dey S, Sheikhbahaei S, Hafezi-Nejad N, Kumar GA, Sreeramareddy CT, Dandona L, Wang H, Vollset SE, Mokdad A, Salomon JA, Lozano R, Vos T, Forouzanfar M, Lopez A, Murray C and Naghavi M: The global burden of cancer 2013. JAMA Oncol 1(4): 505-527, 2015.

2 Siegel RL, Miller KD and Jemal A: Cancer statistics, 2015. CA Cancer J Clin 65(1): 5-29, 2015.

3 Egawa S, Toma H, Ohigashi H, Okusaka T, Nakao A, Hatori T, Maguchi H, Yanagisawa A and Tanaka M: Japan pancreatic cancer registry; 30th year anniversary: Japan Pancreas Society. Pancreas 41(7): 985-992, 2012.

4 Oettle H, Post S, Neuhaus P, Gellert K, Langrehr J, Ridwelski K, Schramm H, Fahlke J, Zuelke C, Burkart C, Gutberlet K, Kettner E, Schmalenberg H, Weigang-Koehler K, Bechstein WO, Niedergethmann M, Schmidt-Wolf I, Roll L, Doerken B and Riess $\mathrm{H}$ : Adjuvant chemotherapy with gemcitabine vs. observation in patients undergoing curative-intent resection of pancreatic cancer: A randomized controlled trial. JAMA 297(3): 267-277, 2007.

5 Ueno H, Kosuge T, Matsuyama Y, Yamamoto J, Nakao A, Egawa S, Doi R, Monden M, Hatori T, Tanaka M, Shimada M and Kanemitsu K: A randomised phase III trial comparing gemcitabine with surgery-only in patients with resected pancreatic cancer: Japanese Study Group of Adjuvant Therapy for Pancreatic Cancer. Br J Cancer 101(6): 908-915, 2009.

6 Oettle H, Neuhaus P, Hochhaus A, Hartmann JT, Gellert K, Ridwelski K, Niedergethmann M, Zulke C, Fahlke J, Arning MB, Sinn M, Hinke A and Riess H: Adjuvant chemotherapy with gemcitabine and long-term outcomes among patients with resected pancreatic cancer: The CONKO-001 randomized trial. JAMA 310(14): 1473-1481, 2013.

7 Uesaka K, Boku N, Fukutomi A, Okamura Y, Konishi M, Matsumoto I, Kaneoka Y, Shimizu Y, Nakamori S, Sakamoto H, Morinaga S, Kainuma O, Imai K, Sata N, Hishinuma S, Ojima $\mathrm{H}$, Yamaguchi R, Hirano S, Sudo T and Ohashi Y: Adjuvant chemotherapy of s-1 versus gemcitabine for resected pancreatic cancer: A phase 3, open-label, randomised, non-inferiority trial (JASPAC 01). Lancet 388(10041): 248-257, 2016.

8 Sohn TA, Yeo CJ, Cameron JL, Koniaris L, Kaushal S, Abrams RA, Sauter PK, Coleman J, Hruban RH and Lillemoe KD: Resected adenocarcinoma of the pancreas-616 patients: Results, outcomes, and prognostic indicators. J Gastrointest Surg 4(6): 567-579, 2000.

9 Howard TJ, Krug JE, Yu J, Zyromski NJ, Schmidt CM, Jacobson LE, Madura JA, Wiebke EA and Lillemoe KD: A marginnegative $\mathrm{r} 0$ resection accomplished with minimal postoperative complications is the surgeon's contribution to long-term survival in pancreatic cancer. J Gastrointest Surg 10(10): 1338-1345; discussion 1345-1336, 2006. 
10 Ghaneh P, Kleeff J, Halloran CM, Raraty M, Jackson R, Melling J, Jones O, Palmer DH, Cox TF, Smith CJ, O'Reilly DA, Izbicki JR, Scarfe AG, Valle JW, McDonald AC, Carter R, Tebbutt NC, Goldstein D, Padbury R, Shannon J, Dervenis C, Glimelius B, Deakin M, Anthoney A, Lerch MM, Mayerle J, Olah A, Rawcliffe CL, Campbell F, Strobel O, Buchler MW and Neoptolemos JP: The impact of positive resection margins on survival and recurrence following resection and adjuvant chemotherapy for pancreatic ductal adenocarcinoma. Ann Surg, 2017. doi: 10.1097/SLA.0000000000002557

11 Tempero MA, Malafa MP, Al-Hawary M, Asbun H, Bain A, Behrman SW, Benson AB, 3rd, Binder E, Cardin DB, Cha C, Chiorean EG, Chung V, Czito B, Dillhoff M, Dotan E, Ferrone CR, Hardacre J, Hawkins WG, Herman J, Ko AH, Komanduri S, Koong A, LoConte N, Lowy AM, Moravek C, Nakakura EK, O'Reilly EM, Obando J, Reddy S, Scaife C, Thayer S, Weekes CD, Wolff RA, Wolpin BM, Burns J and Darlow S: Pancreatic Adenocarcinoma, Version 2.2017, NCCN Clinical Practice Guidelines in Oncology. J Natl Compr Canc Netw 15(8): 10281061, 2017.

12 Varadhachary GR, Tamm EP, Abbruzzese JL, Xiong HQ, Crane $\mathrm{CH}$, Wang H, Lee JE, Pisters PW, Evans DB and Wolff RA: Borderline resectable pancreatic cancer: Definitions, management, and role of preoperative therapy. Ann Surg Oncol 13(8): 10351046, 2006.

13 Katz MH, Marsh R, Herman JM, Shi Q, Collison E, Venook AP, Kindler HL, Alberts SR, Philip P, Lowy AM, Pisters PW, Posner MC, Berlin JD and Ahmad SA: Borderline resectable pancreatic cancer: Need for standardization and methods for optimal clinical trial design. Ann Surg Oncol 20(8): 2787-2795, 2013.

14 Tempero MA, Malafa MP, Behrman SW, Benson AB, 3rd, Casper ES, Chiorean EG, Chung V, Cohen SJ, Czito B, Engebretson A, Feng M, Hawkins WG, Herman J, Hoffman JP, Ko A, Komanduri S, Koong A, Lowy AM, Ma WW, Merchant NB, Mulvihill SJ, Muscarella P, 2nd, Nakakura EK, Obando J, Pitman MB, Reddy S, Sasson AR, Thayer SP, Weekes CD, Wolff RA, Wolpin BM, Burns JL and Freedman-Cass DA: Pancreatic Adenocarcinoma, version 2.2014: Featured updates to the NCCN guidelines. J Natl Compr Canc Netw 12(8): 1083-1093, 2014.

15 Sobin LH WC: TNM Classification of Malignant Tumours. Sixth Edition. Wiley: New York, 2002.

16 National Cancer Institute: Common Terminology Criteria for Adverse Events v.4.0 (CTCAE). Available at:http://ctep.cancer.gov/ protocolDevelopment/electronic_applications/ctc.htm. Accessed November 122017

17 Therasse P, Arbuck SG, Eisenhauer EA, Wanders J, Kaplan RS, Rubinstein L, Verweij J, Van Glabbeke M, van Oosterom AT, Christian MC and Gwyther SG: New guidelines to evaluate the response to treatment in solid tumors. European Organization for Research and Treatment of cancer, National Cancer Institute of the United States, National Cancer Institute of Canada. J Natl Cancer Inst 92(3): 205-216, 2000.

18 Strasberg SM, Drebin JA and Linehan D: Radical antegrade modular pancreatosplenectomy. Surgery 133(5): 521-527, 2003.

19 Katz MH, Wang H, Balachandran A, Bhosale P, Crane CH, Wang X, Pisters PW, Lee JE, Vauthey JN, Abdalla EK, Wolff R, Abbruzzese J, Varadhachary G, Chopin-Laly X, Charnsangavej $\mathrm{C}$ and Fleming JB: Effect of neoadjuvant chemoradiation and surgical technique on recurrence of localized pancreatic cancer. J Gastrointest Surg 16(1): 68-78; discussion 78-69, 2012.
20 Dindo D, Demartines N and Clavien PA: Classification of surgical complications: A new proposal with evaluation in a cohort of 6336 patients and results of a survey. Ann Surg 240(2): 205-213, 2004.

21 Bassi C, Dervenis C, Butturini G, Fingerhut A, Yeo C, Izbicki J, Neoptolemos J, Sarr M, Traverso W and Buchler M: Postoperative pancreatic fistula: An International Study Group (ISGPF) definition. Surgery 138(1): 8-13, 2005.

22 Evans DB, Rich TA, Byrd DR, Cleary KR, Connelly JH, Levin B, Charnsangavej C, Fenoglio CJ and Ames FC: Preoperative chemoradiation and pancreaticoduodenectomy for adenocarcinoma of the pancreas. Arch Surg 127(11): 1335-1339, 1992.

23 Katz MH, Pisters PW, Evans DB, Sun CC, Lee JE, Fleming JB, Vauthey JN, Abdalla EK, Crane CH, Wolff RA, Varadhachary GR and Hwang RF: Borderline resectable pancreatic cancer: The importance of this emerging stage of disease. J Am Coll Surg 206(5): 833-846; discussion 846-838, 2008.

24 Takahashi H, Ohigashi H, Gotoh K, Marubashi S, Yamada T, Murata $\mathrm{M}$, Ioka $\mathrm{T}$, Uehara $\mathrm{H}$, Yano $\mathrm{M}$ and Ishikawa $\mathrm{O}$ : Preoperative gemcitabine-based chemoradiation therapy for resectable and borderline resectable pancreatic cancer. Ann Surg 258(6): 1040-1050, 2013.

25 Turrini O, Ychou M, Moureau-Zabotto L, Rouanet P, Giovannini M, Moutardier V, Azria D, Delpero JR and Viret F: Neoadjuvant docetaxel-based chemoradiation for resectable adenocarcinoma of the pancreas: New neoadjuvant regimen was safe and provided an interesting pathologic response. Eur J Surg Oncol 36(10): 987-992, 2010.

26 Stokes JB, Nolan NJ, Stelow EB, Walters DM, Weiss GR, de Lange EE, Rich TA, Adams RB and Bauer TW: Preoperative capecitabine and concurrent radiation for borderline resectable pancreatic cancer. Ann Surg Oncol 18(3): 619-627, 2011.

27 Satoi S, Toyokawa H, Yanagimoto H, Yamamoto T, Kamata M, Ohe C, Sakaida N, Uemura Y, Kitade H, Tanigawa N, Inoue K, Matsui $\mathrm{Y}$ and Kwon AH: Neo-adjuvant chemoradiation therapy using S-1 followed by surgical resection in patients with pancreatic cancer. J Gastrointest Surg 16(4): 784-792, 2012.

28 Kim EJ, Ben-Josef E, Herman JM, Bekaii-Saab T, Dawson LA, Griffith KA, Francis IR, Greenson JK, Simeone DM, Lawrence TS, Laheru D, Wolfgang CL, Williams T, Bloomston M, Moore MJ, Wei A and Zalupski MM: A multi-institutional phase 2 study of neoadjuvant gemcitabine and oxaliplatin with radiation therapy in patients with pancreatic cancer. Cancer 119(15): 26922700, 2013.

29 Shewach DS, Hahn TM, Chang E, Hertel LW and Lawrence TS: Metabolism of 2',2'-difluoro-2'-deoxycytidine and radiation sensitization of human colon carcinoma cells. Cancer Res 54(12): 3218-3223, 1994.

30 Leone F, Gatti M, Massucco P, Colombi F, Sperti E, Campanella D, Regge D, Gabriele P, Capussotti L and Aglietta M: Induction gemcitabine and oxaliplatin therapy followed by a twice-weekly infusion of gemcitabine and concurrent external-beam radiation for neoadjuvant treatment of locally advanced pancreatic cancer: A single-institutional experience. Cancer 119(2): 277-284, 2013.

31 Satoi S, Yanagimoto H, Toyokawa H, Takahashi K, Matsui Y, Kitade H, Mergental H, Tanigawa N, Takai S and Kwon AH: Surgical results after preoperative chemoradiation therapy for patients with pancreatic cancer. Pancreas 38(3): 282-288, 2009. 
32 Kobayashi M, Mizuno S, Murata Y, Kishiwada M, Usui M, Sakurai H, Tabata M, Ii N, Yamakado K, Inoue H, Shiraishi T, Yamada $\mathrm{T}$ and Isaji S: Gemcitabine-based chemoradiotherapy followed by surgery for borderline resectable and locally unresectable pancreatic ductal adenocarcinoma: Significance of the CA19-9 reduction rate and intratumoral human equilibrative nucleoside transporter 1 expression. Pancreas 43(3): 350-360, 2014.

33 Hall MD, Schultheiss TE, Smith DD, Fakih MG, Wong JY and Chen YJ: Effect of increasing radiation dose on pathologic complete response in rectal cancer patients treated with neoadjuvant chemoradiation therapy. Acta Oncol 55(12): 13921399, 2016.

34 Runau F, Collins A, Fenech GA, Ford E, Dimitriou N, Chaudhri S and Yeung JM: A single institution's long-term follow-up of patients with pathological complete response in locally advanced rectal adenocarcinoma following neoadjuvant chemoradiotherapy. Int J Colorectal Dis 32(3): 341-348, 2017.

35 Tomasello G, Petrelli F, Ghidini M, Pezzica E, Passalacqua R, Steccanella F, Turati L, Sgroi G and Barni S: Tumor regression grade and survival after neoadjuvant treatment in gastroesophageal cancer: A meta-analysis of 17 published studies. Eur J Surg Oncol 43(9): 1607-1616, 2017.
36 Groot VP, Rezaee N, Wu W, Cameron JL, Fishman EK, Hruban RH, Weiss MJ, Zheng L, Wolfgang CL and He J: Patterns, timing, and predictors of recurrence following pancreatectomy for pancreatic ductal adenocarcinoma. Ann Surg 267(5): 936945, 2018.

37 Katz MH, Fleming JB, Bhosale P, Varadhachary G, Lee JE, Wolff R, Wang H, Abbruzzese J, Pisters PW, Vauthey JN, Charnsangavej C, Tamm E, Crane $\mathrm{CH}$ and Balachandran A: Response of borderline resectable pancreatic cancer to neoadjuvant therapy is not reflected by radiographic indicators. Cancer 118(23): 5749-5756, 2012.
Received May 4, 2018

Revised June 3, 2018

Accepted June 5, 2018 